\title{
Familial Marcus Gunn phenomenon
}

\author{
T. H. KIRKHAM \\ Sheffield Royal Infirmary
}

There have been few reports of Marcus Gunn's phenomenon occurring as a familial con- $\vec{\ominus}$ dition. This report concerns a brother and sister both of whom demonstrate Marcus $\vec{\omega}$ Gunn's anomaly affecting the left upper lid. Both parents are normal. Photographic evidence shows their maternal aunt, who now lives abroad, to have left ptosis. Whether or: not this was associated with the Marcus Gunn phenomenon cannot be recalled. No other affected family members are known.

\section{Case I}

A boy aged 15 had a bilateral medial rectus recession performed in 1956 for an alternating, predominantly left convergent strabismus. The visual acuity was $6 / 9$ with $+4.5 \mathrm{D}$ sph., I $\mathrm{D}$ cyl., axis $90^{\circ}$ in the right eye and $6 / 9$ with $+4 \mathrm{D}$ sph., $+0.5 \mathrm{D}$ cyl., axis $90^{\circ}$ in the left. There was a $\overrightarrow{\mathscr{0}}$ residual left convergent strabismus of $7^{\circ}$. In the primary position left ptosis was present, the palpe- I bral apertures measuring $24 \times 10 \mathrm{~mm}$. right and $24 \times 8 \mathrm{~mm}$. left. On looking upwards a full range of levator action was present on either side. On moving the jaw to the right, the left upper lid retracted rapidly some $3 \mathrm{~mm}$. and immediately returned to its original position. Widely opening the mouth did not produce the phenomenon, nor was the ptosis increased by moving the jaw to the left. Neurological examination revealed no other abnormalities.

\section{Case 2}

A girl aged 16, the sister of Case $\mathrm{I}$, had visual acuity $6 / 9$ with $+4 \mathrm{D}$ sph., $+\mathrm{I} \cdot 5 \mathrm{D}$ cyl., axis $90^{\circ}$ in the right eye and $6 / 9$ with $+4 \mathrm{D}$ sph., $+\mathrm{I} \mathrm{D}$ cyl., axis $90^{\circ}$ in the left. There was a left convergent strabismus of $15^{\circ}$. Left ptosis was present, the palpebral apertures measuring $24 \times 9 \mathrm{~mm}$. right and $24 \times 7 \mathrm{~mm}$. left in the primary position. A good range of levator action was present on either side. When the jaw was moved to the right, the left upper lid retracted rapidly some $3 \mathrm{~mm}$. and then fell back to its original position. Other jaw movements had no effect on the ptosis. No other abnormalities were present.

\section{Discussion}

In the majority of cases of Marcus Gunn phenomenon described in the literature the ptosis is increased by moving the jaw to the affected side and lid retraction occurs on jaw movement to the opposite side (Duke-Elder, 1964). Of the familial cases reported, a girl and her grandfather described by Łaska (I960) demonstrated this typical picture, as did a girl and her aunt described by Kanter (1955). In the family reported by Falls, Kruse, and Cotterman (1949), lid retraction occurred on protrusion of the jaw although lateral jaw movement had no effect on the ptosis. The present cases showed lid retraction on moving the jaw to the opposite side but no other effects of jaw movement could be elicited.

These sibs are of interest on two further accounts. First, there was a good range of levator action present on the affected side unassociated with jaw movements which is 
contrary to the usual description of an apparently ptotic lid demonstrating only synkinetic movements. Secondly, the association of Marcus Gunn phenomenon with a convergent strabismus is not mentioned by Duke-Elder (1964) apart from the case described by Garkal (I96I) with a convergent strabismus which disappeared on elevation of the lid. There was no such synkinesis in the sibs reported here.

\section{Summary}

Two sibs with Marcus Gunn phenomenon are described who showed unusual features. Both cases had lid retraction on movement of the jaw to the opposite side. A good range of voluntary levator action was present, and both had a convergent strabismus.

I wish to thank Mr. A. Stanworth for permission to examine the patients under his care.

\section{References}

DUKE-ELDER, s. (1964) "System of Ophthalmology", vol. 3, pt. 2, p. 900. Kimpton, London falls, H. F., KRUSE, w. T., and cotterman, c. w. (1949) Amer. F. Ophthal., 32, no. 6, pt. 2, p. 53 GARKal, A. s. (1961) Brit. J. Ophthal., 45, 566

KAnter, D. (1955) Klin. Mbl. Augenheilk., 126, 50

EASKA, M. (1960) Klin. oczna, 30, 393 